\title{
Oxidative Stress Associated with Indoor Air Pollution and Sick Building Syndrome-Related Symptoms among Office Workers in Taiwan
}

\author{
Chung-Yen Lu, Yee-Chung Ma, and Jia-Min Lin \\ Institute of Environmental Health, National Taiwan University College of Public Health, Taipei
}

\section{Chung-Yi Li}

Department of Public Health, Fu Jen Catholic University College of Medicine, Taipei

\author{
Reuy S. Lin \\ Institute of Preventive Medicine, National Taiwan University College of Public Health, Taipei
}

\section{Fung-Chang Sung}

Institutes of Environmental Health and Preventive Medicine, National Taiwan University College of Public Health, Taipei, and Institute of Environmental Health, China Medical University College of

Public Health, Taichung, Taiwan

\begin{abstract}
This study investigated whether sick building syndrome (SBS) complaints and indoor air pollution for office workers are associated with oxidative stress indicated by urinary 8hydroxydeoxyguanosine (8-OHdG). With informed consent, 389 employees in 87 government offices of 8 high-rise buildings in Taipei city completed self-reported questionnaires on SBS complaints at work in the past month. Urinary 8-OHdG was determined for each study participant and on-site air pollutants were measured for each office in both indoor and outdoor air. The results showed that urinary 8-OHdG had significant associations with volatile organic compounds and carbon dioxide levels in offices, and with urinary cotinine levels. The mean urinary 8-OHdG level was also significantly higher in participants with SBS symptoms than in those without such complaints (6.16 vs. $5.45 \mu \mathrm{g} / \mathrm{g}$ creatinine, $p=.047)$. The mean 8-OHdG increased as the number of SBS symptoms increased. The multivariate logistic regression analyses showed that the adjusted odds ratios (OR) in relation to micrograms per gram creatinine increase in 8-OHdG were statistically significant for eye dryness (1.12), upper respiratory syndrome (1.17) with particularly nose itching (1.25), sneezing (1.51), dry throat (1.21), skin dryness (1.31), and dizziness (1.19). This study indicates that the 8-OHdG level was significantly associated with SBS complaints after controlling for air pollution and smoking. Whether the 8-OHdG can be used as an effective predictor for SBS symptoms deserves further study.
\end{abstract}

Workers are considered to have sick building syndrome (SBS) when they suffer from symptoms related to eyes, nose, and throat, dry skin, headache, and/or lethargy inside a building, and the symptom complaints may ease when workers leave the

Received 14 June 2006; accepted 6 August 2006.

The authors gratefully acknowledge all the participants in this study. This work was supported by the National Science Council, Executive Yuan, grant NSC 92-2320-B-039-054.

Address correspondence to Fung-Chang Sung, $\mathrm{PhD}$, MPH, Professor and Director, Institute of Environmental Health, China Medical University College of Public Health, 91 Hsueh-Shih Road, Taichung 404, Taiwan. E-mail: fcsung@ mail.cmu.edu.tw buildings (Levin, 1989). Many previous studies were conducted to investigate the etiology of the SBS, but the risk factors causally associated with SBS remain debatable (Kreiss, 1990; Menzies et al., 1997; Redlich et al., 1997; Teculescu et al., 1998; Seidner, 1999; Tearle, 1999; Mahmoudi \& Gershwin, 2000; Niven et al., 2000; Yassi et al., 2001). Among findings, insufficient ventilation and uncomfortable temperature and humidity have been thought to be the major factors associated with the SBS (Bourbeau et al., 1997; Backman \& Haghighat, 1999; Seppänen et al., 1999; Apte et al., 2000; Engvall et al., 2001; Burge, 2004). Insufficient ventilation in officices may cause indoor air pollutants to accumulate gradually. Previous studies have indicated that both carbon dioxide $\left(\mathrm{CO}_{2}\right)$ and volatile organic compounds 
(VOCs) are the major air pollutants resulting from insufficient ventilation in offices (Apte et al., 2000; Burge, 2004). Nonetheless, little has been known regarding specific human biomarkers, if any, that may be associated with the occurrence of SBS.

One way to improve the acknowledgment of the occurrence of SBS is to identify a marker that may best reflect the exposure of certain air pollutants as a result of insufficient ventilation. Reactive oxygen species (ROS) are components widely found in many of the air pollutants (van Klaveren \& Nemery, 1999; Huang et al., 2005), and can cause oxidative damage to lipids, proteins, and nucleic acids, resulting in oxidative stress (Loft et al., 1992; Wu et al., 2004). We hypothesized that oxidative stress can serve as a predictor of SBS. Urinary 8-hydroxydeoxyguanosine (8-OHdG) has been known to be a biological marker of oxidative stress on DNA. As a result of exposure to ROS, 8-OHdG can be excised with hydroxylation by constitutive enzymatic repair systems and excreted in the urine (Shigenaga et al., 1989; Floyd et al., 1990; Fraga et al., 1990). Urban air pollution, tobacco smoke, environmental tobacco smoke (ETS), VOCs, and ionization radiation have been associated with the rise of urinary 8-OHdG levels (Samet et al., 1987; Anderson et al., 1991; Wilson et al., 1993; Tagesson et al., 1995, 1996; Calderon-Garciduenas et al., 1999; Carstensen et al., 1999).

The investigation of etiology of SBS in office buildings remains an important research issue. To our best knowledge, there have been no previous studies that investigated the association of oxidative stress with SBS symptoms. This study, therefore, was conducted to examine whether poor air quality may be associated with an office worker's oxidative stress, and subsequently with SBS symptoms. The oxidative stress status of individual worker was indicated by the concentration of urinary $8-\mathrm{OHdG}$. In addition, we used a self-reported questionnaire to assess a worker's SBS complaints.

\section{MATERIALS AND METHODS}

\section{Study Design and Study Subjects}

From November 2003 to June 2004, we randomly selected 16 government agencies and commercial organizations in high-rise buildings in the city center of Taipei, for recruitment of study subjects and on-site measurements of indoor air pollutants. Five organizations declined to participate. Three of the remaining 11 institutions declined to provide urinary specimens. An invitational letter explaining the study was delivered to potential participants at 87 office units of the rest 8 organizations. With informed consent, 398 persons responded to this study (response rate $61.7 \%$ ). Each of these office workers was asked to provide a spot urine sample for the measurement of 8-OHdG and completed a self-reported questionnaire on various variables including SBS complaints. The urine sample was collected from each participant at the end of the work day. Samples were transported in a cold box at $4{ }^{\circ} \mathrm{C}$ to the laboratory and stored at $-80^{\circ} \mathrm{C}$ until analysis. This study was approved by an ad hoc review committee organized by the National Science Council, Taiwan.

\section{Questionnaire Survey and Air Quality Examination}

This study used a questionnaire to collect the information on typical SBS symptoms adapted from the recommendations of the WHO Regional Office for Europe Report (World Health Organization, 1986). The questionnaire inquired about SBS experienced in the past month, specifically for eyes, upper and lower respiratory tract, skin, and nonspecific complaints. Information on sociodemographic status (sex, age, education, and job), lifestyle (smoking, environmental tobacco smoke), recent airway infections, and medication (asthma, nasosinusitis, atopic rhinitis, and allergy) was also obtained through questionnaire.

On-site measurements of air pollutants for each office were performed for carbon dioxide $\left(\mathrm{CO}_{2}\right)$ (inside and outside the office), carbon monoxide, total volatile organics (TVOC), temperature, and humid. $\mathrm{CO}_{2}$ measures were standardized in the range of 0-5000 ppm (Q-TRAK IAQ model 8551, TSI, Inc., Shoreview, MN), and VOCs were standardized with 102 categories (PGM-7240, RAE System, Sunnyvale, CA). Ventilation efficiency in each office was represented by the 8 -h average difference between indoor and outdoor $\mathrm{CO}_{2}$ levels $\left(\mathrm{dCO}_{2}=\mathrm{CO}_{2 \text { indoor }}-\mathrm{CO}_{2 \text { outdoor }}\right)$.

\section{Determinations of Urinary Creatinine, Cotinine, and 8-OHdG}

Specimens of urine were stored at $-80^{\circ} \mathrm{C}$ and assayed within 1 to 2 months. Thawed samples were pretreated with a centrifuge at $2000 \mathrm{rpm}$ for $10 \mathrm{~min}$ to remove the particulate matter. The urinary creatinine values in samples were determined with an automatic analyzer (Hitachi 7250, Tokyo) based on the Jaffe colorimeter reaction (Nerurkar \& Sahasrabudhe, 1960; Chuang et al., 2003).

Both VOCs and tobacco smoking are potential materials associated with the 8-OHdG levels in urine. We also determined urinary cotinine to assay the levels of smoking and environmental tobacco smoke exposures among the participants. Urinary cotinine was determined by direct barbituric acid (DBA) assay on the basis of rapid analysis based on the König reaction (Benowitz, 1996; Haufroid \& Lison, 1998; Willers et al., 2004). At room temperature, $400 \mu \mathrm{l}$ of each sample or standard solution was used for analysis. The cotinine concentration in the sample was determined by comparing the absorbance values at $550 \mathrm{~nm}$ against a calibration curve generated by $5,10,50,100$, 150,200 , and $250 \mu \mathrm{mol} / \mathrm{L}$ cotinine, expressed as micrograms per gram creatinine.

Urinary 8-OHdG levels were determined by the OXIS Research enzyme-linked immunosorbent assay (ELISA) kit (Japan Institute for the Control of Aging, Shizuoka, Japan) on the basis of highly sensitivity and specificity, and rapid analysis. At room temperature, $50 \mu \mathrm{l}$ of 8-OHdG monoclonal antibody and $50 \mu \mathrm{l}$ of each urine sample or standard solution were loaded onto a microtiter plate that was precoated with 8-OHdG for assay (Yin et al., 1995). The determination ranged from 0.5 to $200 \mathrm{ng} / \mathrm{ml}$, generated using $0.5,2,8,20,80$, and $200 \mathrm{ng} / \mathrm{ml} 8-\mathrm{OHdG}$, expressed as micrograms per gram creatinine. 


\section{Statistical Analysis}

In statistical analyses, we first used Pearson's $\chi^{2}$ test to test the associations between 8-OHdG levels of study participants and selected covariates, including sociodemographic status, lifestyle, and office environmental status and air quality. The level of $8-\mathrm{OHdG}$ was presented in a tertile distribution $(\leq 3.79$, $3.80-6.63,>6.63 \mu \mathrm{g} / \mathrm{g}$ creatinine). Mean concentrations of indoor air pollutants and $\mathrm{CO}_{2}$, temperature, and tobacco smoke exposure (cotinine) were compared, using one-way analysis of variance (ANOVA) by the level of $8-\mathrm{OHdG}$. We also used Student's $t$-test to compare the 8-OHdG level in association with the specific SBS symptoms, including eyes (eye dryness and eye irritation), upper respiratory tract (nose itching, runny nose, stuffy nose, sneezing, and dry throat), lower respiratory tract (difficulty in breathing), skin (skin dryness), and nonspecific symptoms (headache, tiredness, difficulty concentrating, angry easily, and dizziness). A study participant was considered to suffer from SBS symptoms if he or she reported having one or more selected symptoms for at least 1-3 days per week at work in the office in the previous month, but the symptoms improved or disappeared at the end of the working day and/or on weekends or vacations. The prevalence rates of SBS symptoms were calculated for the selected symptoms individually and as a group. Finally, simple and step-down multivariate logistic regression (MLR) models were constructed using each of the SBS symptoms as the dependent variables, and the creatinine adjusted 8-OHdG level as independent variable. The odds ratio (OR) and corresponding 95\% confidence interval (CI) were calculated. The final MLR analysis was performed controlling for potential confounding factors, including gender, age, presence of carpet in workspace, whether sensitive to tobacco smoke and air pollutants, difference between indoor and outdoor carbon dioxide, and urinary cotinine concentrations. Air pollution and tobacco smoking have been considered the important factors associated with urinary $8-\mathrm{OHdG}$ levels. In this study we found that urinary 8-OHdG levels have a stronger association with $\mathrm{CO}_{2}$ than with TVOC, and these two groups of substances had a significant collinear relationship. We therefore included $\mathrm{CO}_{2}$ and urinary cotinine as covariates in the multivariate analysis. Probability values less than $5 \%$ were considered statistically significant. All data analyses used SPSS for Windows version 10.0 (SPSS, Inc., Chicago).

\section{RESULTS}

\section{Self-Reported Symptoms}

Study participants were predominantly women $(77.1 \%)$. In the tertile distribution of $8-\mathrm{OHdG}, 48.3 \%$ men versus $28.7 \%$ women had their $8-\mathrm{OHdG}$ in the highest tertile, that is, $>6.63 \mu \mathrm{g} / \mathrm{g}$ creatinine (Table 1 ). The urinary $8-\mathrm{OHdG}$. levels were also higher in active smokers than in nonsmokers and exsmokers, The study participants who were sensitive to tobacco smoke and air pollutants also tended to have significantly lower level of 8-OHdG.

\section{Urinary 8-OHdG Level}

Table 2 shows that the urinary $8-\mathrm{OHdG}$ concentrations were strongly associated with certain indoor air pollutants and urinary cotinine concentrations. The study participants with higher tertiles of 8-OHdG tended to work in offices with higher concentrations of $\mathrm{dCO}_{2}$ and TVOC. The mean TVOC in the offices exposed by the study participants in the highest tertile of $8-\mathrm{OHdG}$ was approximately 8 times higher than that exposed by the participants with the lowest tertile (2580 vs. $302 \mathrm{ppb}$ ). Additionally, the average urinary cotinine concentrations were $1.95,3.15$, and $6.22 \mu \mathrm{g} / \mathrm{g}$ creatinine, respectively, with the corresponding lowest, middle, and highest tertiles of 8-OHdG.

The prevalence rates of SBS symptoms were the highest for nonspecific conditions (29.0\% or $111 / 389)$, and lowest for skin (1.4\% or $6 / 389$ ) (data not shown). The symptom prevalence rates for upper respiratory tract, lower respiratory tract, skin, and others such as tiredness, difficulty in concentrating, angry easily, and dizziness were estimated at $15.7 \%, 6.7 \%, 1.5 \%$, $20.4 \%, 13.9 \%, 12.7 \%$, and $6.5 \%$, respectively. Table 3 shows that the means \pm standard deviations of urinary $8-\mathrm{OHdG}$ concentration was greater for study participants with one or more SBS complaints than those without such complaints $(6.16 \pm 3.81$ vs. $5.45 \pm 3.10 \mu \mathrm{g} / \mathrm{g}$ creatinine $)(p=.047)$. Among specific SBS complaints associated with significantly elevated levels of $8-\mathrm{OHdG}$, the highest level was observed for skin dryness, followed by headache, sneezing, nose itching, stuffy nose, dry throat, dizziness, angry easily, tiredness, and difficulty concentrating, with a mean ranging from 11.2 (skin dryness) to $7.43 \mu \mathrm{g} / \mathrm{g}$ creatinine (difficulty concentrating). On the other hand, we noted that participants with lower respiratory tract symptoms had a mean $8-\mathrm{OHdG}$ level similar to those without such symptoms $(p=.828)$.

To assess the relationship between severity of SBS symptoms and level of $8-\mathrm{OHdG}$ level, Table 4 shows the mean $8-\mathrm{OHdG}$ according to number of SBS symptoms. The study participants with only one SBS symptom had a mean 8-OHdG level of $5.11 \pm 3.02 \mu \mathrm{g} / \mathrm{g}$ creatinine, which is somewhat lower than that of participants free from any SBS complaints. The 8-OHdG level concentration then increased monotonically with an increase of number of SBS symptoms (Table 4).

We used both univariate and multivariate logistic regressions models to estimate the relative risk of specific SBS in association with per unit increase of $8-\mathrm{OHdG}$ (Table 5). After controlling for age, gender, presence of carpet, sensitivity to tobacco smoke and air pollutants, difference between indoor and outdoor carbon dioxide, and urinary cotinine concentrations, the highest adjusted OR associated with micrograms per gram creatinine increase in urinary $8-\mathrm{OHdG}$ level was noted for sneezing $(\mathrm{OR}=1.51,95 \% \mathrm{CI}=1.21-1.87)$, followed by skin dryness, nose itching, dizziness and eye dryness $(\mathrm{OR}=1.12$, $95 \% \mathrm{CI}=1.02-1.23$ ). 
TABLE 1

Tertile distribution of 8-hydroxydeoxyguanosine (8-OHdG) according to selected characteristics

\begin{tabular}{|c|c|c|c|c|c|}
\hline \multirow[b]{2}{*}{ Variables } & \multirow[b]{2}{*}{$N$} & \multicolumn{3}{|c|}{ 8-OHdG, $\mu \mathrm{g} / \mathrm{g}$ creatinine } & \multirow[b]{2}{*}{$p$} \\
\hline & & $\leq 3.79, n(\%)$ & $3.80-6.63, n(\%)$ & $>6.63, n(\%)$ & \\
\hline \multicolumn{6}{|l|}{ Sex } \\
\hline Male & 89 & $24(27.0)$ & $22(24.7)$ & $43(48.3)$ & $.002^{b}$ \\
\hline Female & 300 & $108(27.0)$ & $106(35.3)$ & $86(28.7)$ & \\
\hline \multicolumn{6}{|l|}{ Age, years } \\
\hline$<40$ & 269 & $84(31.2)$ & $90(33.5)$ & $95(35.3)$ & .204 \\
\hline$\geq 40$ & 120 & $48(40.0)$ & $38(31.7)$ & $34(28.3)$ & \\
\hline \multicolumn{6}{|l|}{ Years at work } \\
\hline$\leq 4$ & 211 & $66(31.3)$ & $77(36.5)$ & $68(32.2)$ & .237 \\
\hline$>4$ & 178 & $66(37.1)$ & $51(28.7)$ & $61(34.3)$ & \\
\hline \multicolumn{6}{|l|}{ Smoking habits } \\
\hline Never/former & 344 & $132(38.4)$ & $121(35.2)$ & $91(26.5)$ & $<.001^{b}$ \\
\hline Current & 45 & 0 & 7 (15.6) & $38(84.4)$ & \\
\hline \multicolumn{6}{|l|}{ Dust allergy } \\
\hline No & 291 & $97(33.3)$ & $101(34.7)$ & $93(32.0)$ & .413 \\
\hline Yes & 98 & $35(35.7)$ & 27 (27.6) & $36(36.7)$ & \\
\hline \multicolumn{6}{|l|}{ Animal allergy } \\
\hline No & 356 & 117 (32.9) & $119(33.4)$ & $120(33.7)$ & .344 \\
\hline Yes & 33 & 15 (45.5) & $9(27.3)$ & $9(27.3)$ & \\
\hline \multicolumn{6}{|c|}{ Sensitive to tobacco smoke } \\
\hline No & 122 & 24 (19.7) & $39(32.0)$ & $59(48.4)$ & $<.001^{b}$ \\
\hline Yes & 267 & $108(40.4)$ & 89 (33.3) & $70(26.2)$ & \\
\hline \multicolumn{6}{|c|}{ Sensitive to air pollutants } \\
\hline No & 138 & $35(25.4)$ & $48(34.8)$ & $55(39.9)$ & $.021^{b}$ \\
\hline Yes & 251 & 97 (38.6) & $80(31.9)$ & 74 (29.5) & \\
\hline \multicolumn{6}{|l|}{ Asthma } \\
\hline No & 375 & $125(33.3)$ & $124(33.1)$ & $126(33.6)$ & .196 \\
\hline Yes & 14 & 7 (50.0) & 4 (28.6) & $3(21.4)$ & \\
\hline \multicolumn{6}{|l|}{ Nasosinusitis } \\
\hline No & 360 & $118(32.8)$ & $119(33.1)$ & $123(34.2)$ & .182 \\
\hline Yes & 29 & $14(48.3)$ & $9(31.0)$ & $6(20.7)$ & \\
\hline \multicolumn{6}{|l|}{ Atopic rhinitis } \\
\hline No & 277 & $95(34.3)$ & $95(34.3)$ & 87 (31.4) & .473 \\
\hline Yes & 112 & 37 (33.0) & $33(29.5)$ & $42(37.5)$ & \\
\hline \multicolumn{6}{|l|}{ Stress at work } \\
\hline No & 350 & $119(34.0)$ & 115 (32.9) & $116(33.1)$ & .996 \\
\hline Yes & 39 & $13(33.3)$ & 13 (33.3) & 13 (33.3) & \\
\hline \multicolumn{6}{|c|}{ Social support from family } \\
\hline No & 145 & $79(32.4)$ & $45(31.0)$ & 47 (32.4) & .687 \\
\hline Yes & 224 & $79(32.4)$ & $83(34.0)$ & $82(33.6)$ & \\
\hline \multicolumn{6}{|c|}{ Carpet in workspace } \\
\hline No & 146 & $65(44.5)$ & $34(23.3)$ & $47(32.2)$ & $.001^{b}$ \\
\hline Yes & 243 & $67(27.6)$ & $94(38.7)$ & $82(33.7)$ & \\
\hline \multicolumn{6}{|c|}{ New decoration in workspace } \\
\hline No & 356 & $117(32.9)$ & $117(32.9)$ & 122(34.3) & .227 \\
\hline Yes & 33 & $15(45.5)$ & $11(33.3)$ & 7 (21.2) & \\
\hline
\end{tabular}


TABLE 1

Tertile distribution of 8-hydroxydeoxyguanosine (8-OHdG) according to selected characteristics (Continued)

\begin{tabular}{|c|c|c|c|c|c|}
\hline \multirow[b]{2}{*}{ Variables } & \multirow[b]{2}{*}{$N$} & \multicolumn{3}{|c|}{8 -OHdG, $\mu \mathrm{g} / \mathrm{g}$ creatinine } & \multirow[b]{2}{*}{$p$} \\
\hline & & $\leq 3.79, n(\%)$ & $3.80-6.63, n(\%)$ & $>6.63, n(\%)$ & \\
\hline \multicolumn{6}{|c|}{ Painting recently in workspace } \\
\hline No & 370 & $121(32.7)$ & $123(33.2)$ & $126(34.1)$ & .065 \\
\hline Yes & 19 & $11(57.9)$ & $5(26.3)$ & $3(15.8)$ & \\
\hline \multicolumn{6}{|c|}{ Mold speck in workspace } \\
\hline No & 357 & $122(34.2)$ & $118(33.1)$ & $117(32.8)$ & .860 \\
\hline Yes & 32 & $10(31.3)$ & $10(31.3)$ & $12(37.5)$ & \\
\hline \multicolumn{6}{|c|}{ Exposure to $\mathrm{ETS}^{a}$} \\
\hline No & 326 & $110(33.7)$ & $107(32.8)$ & $109(33.4)$ & .965 \\
\hline Yes & 63 & $22(34.9)$ & $21(33.3)$ & $20(31.7)$ & \\
\hline
\end{tabular}

${ }^{a}$ Environmental tobacco smoke.

${ }^{b}$ Significant difference.

\section{DISCUSSION}

This study used the urinary excretion of $8-\mathrm{OHdG}$ as a marker to assess whether it has an association with SBS related symptoms in office workers. The results showed that the 8-OHdG level was positively and significantly associated with concentrations of $\mathrm{CO}_{2}$ and $\mathrm{VOC}$ at offices. The $8-\mathrm{OHdG}$ level was also significantly elevated among workers with sneezing, headache, skin dryness, dry throat, dizziness, nose itching, stuffy nose, runny nose, tiredness, eye dryness, and upper respiratory tract and nonspecific complaints. A positive doseresponse effect can also be found between $8-\mathrm{OHdG}$ levels and the number of symptoms. These findings tend to indicate that the occurrence of SBS is likely to be associated with oxidative stress.
To examine the oxidative stress, the measurement of 8-OHdG excretion in urine has been used as a viable noninvasive marker. The formation of $8-\mathrm{OHdG}$ involves environmental exposure (traffic exhaust, sunlight, etc.), lifestyle (smoking, betel nut chewing, etc.), physiological factors (gender, age, body mass index $[\mathrm{BMI}]$ ), stress (working conditions), and disease (cancer, systemic lupus erythematosus, arthritis, diabetes mellitus, etc.) (Loft et al., 1992; Witherell et al., 1998; van Zeeland et al., 1999; Kasai et al., 2001; Chuang et al., 2003). The present study showed that the risk factors associated with SBS, somewhat similar to factors associated with the formation of $8-\mathrm{OHdG}$, are complex.

The SBS symptoms first attracted attention in the 1970s associated with ventilation systems in more energy-efficient

TABLE 2

Means and standard deviations (SD) of indoor air pollutants in offices according to tertile levels of urinary 8-hydroxydeoxyguanosine of study participants

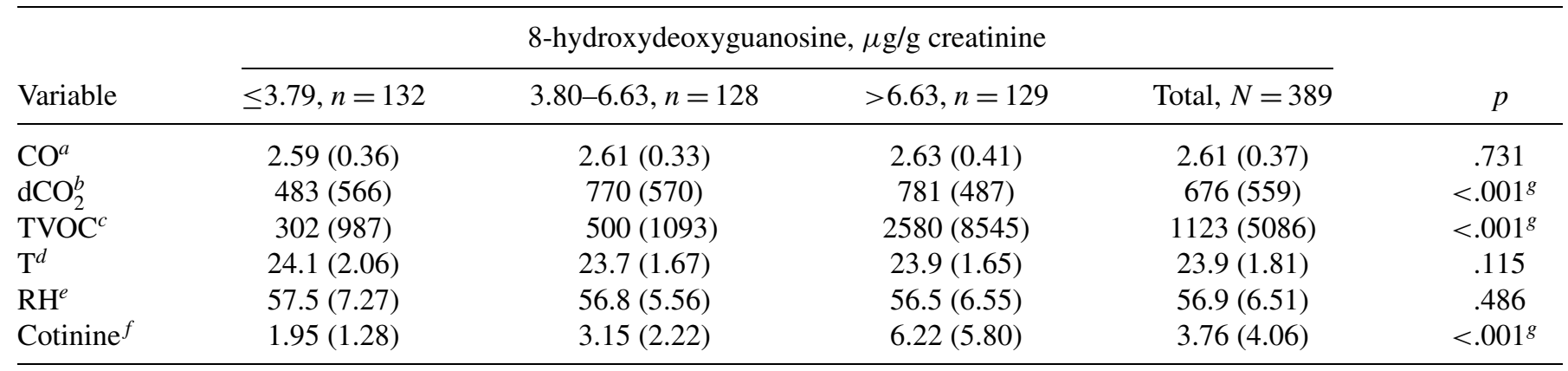

${ }^{a} \mathrm{CO}$, indoor carbon monoxide (ppm).

${ }^{b} \mathrm{dCO}_{2}$, difference between indoor and outdoor carbon dioxide (ppm).

${ }^{c}$ TVOC, indoor total volatile organic compounds (ppb).

${ }^{d} \mathrm{~T}$, temperature $\left({ }^{\circ} \mathrm{C}\right)$.

${ }^{e} \mathrm{RH}$, indoor relative humidity (\%).

${ }^{f}$ Cotinine, urinary cotinine concentrations in participants ( $\mu \mathrm{g} / \mathrm{g}$ creatinine).

${ }^{g}$ Significant difference. 
TABLE 3

Mean and standard deviation (SD) of urinary 8-hydroxydeoxyguanosine levels of study participants according to SBS symptoms

\begin{tabular}{|c|c|c|c|}
\hline \multirow[b]{2}{*}{ Symptom $(n / n)^{a}$} & \multicolumn{2}{|c|}{ Self-rated SBS symptoms } & \multirow[b]{2}{*}{$p$} \\
\hline & Ever, mean $(\mathrm{SD})^{b} \mu \mathrm{g} / \mathrm{g}$ creat. $^{c}$ & Never, mean $(\mathrm{SD})^{b} \mu \mathrm{g} / \mathrm{g}$ creat. $^{c}$ & \\
\hline Eye, any (89/300) & $6.32(3.84)$ & $5.68(3.39)$ & .134 \\
\hline Eye dryness $(74 / 315)$ & $6.62(3.84)$ & $5.64(3.40)$ & $.029^{d}$ \\
\hline Eye irritation (22/367) & $5.60(4.24)$ & $5.84(3.46)$ & .751 \\
\hline Upper respiratory, any $(62 / 327)$ & $8.32(4.30)$ & $5.35(3.13)$ & $<.001^{d}$ \\
\hline Nose itching $(10 / 379)$ & $8.49(4.93)$ & $5.76(3.44)$ & $.015^{d}$ \\
\hline Runny nose (11/378) & $7.73(4.02)$ & $5.77(3.48)$ & .067 \\
\hline Stuffy nose (24/365) & $8.88(4.29)$ & $5.62(3.36)$ & $<.001^{d}$ \\
\hline Sneezing $(10 / 379)$ & $9.12(4.02)$ & $5.74(3.46)$ & $.003^{d}$ \\
\hline Dry throat $(26 / 363)$ & $8.61(4.54)$ & $5.63(3.34)$ & $<.001^{d}$ \\
\hline Lower respiratory, any $(28 / 361)$ & $5.69(3.88)$ & $5.84(3.48)$ & .828 \\
\hline Difficulty in breathing (28/361) & $5.69(3.88)$ & $5.84(3.48)$ & .828 \\
\hline Skin, any $(6 / 383)$ & $11.2(4.78)$ & $5.74(3.43)$ & $<.001^{d}$ \\
\hline Dryness $(6 / 383)$ & $11.2(4.78)$ & $5.74(3.43)$ & $<.001^{d}$ \\
\hline Nonspecific, any (111/278) & $6.91(4.13)$ & $5.39(3.13)$ & $<.001^{d}$ \\
\hline Headache $(7 / 382)$ & $10.9(2.16)$ & $5.73(3.46)$ & $<.001^{d}$ \\
\hline Tiredness $(81 / 308)$ & $7.46(4.10)$ & $5.39(3.21)$ & $<.001^{d}$ \\
\hline Difficulty concentrating (59/330) & $7.43(4.17)$ & $5.56(3.32)$ & $<.001^{d}$ \\
\hline Angry easily (50/339) & $7.69(4.95)$ & $5.55(3.16)$ & $<.001^{d}$ \\
\hline Dizziness $(23 / 366)$ & $8.44(4.72)$ & $5.64(3.33)$ & $<.001^{d}$ \\
\hline All, any $(205 / 184)$ & $6.16(3.81)$ & $5.45(3.10)$ & .047 \\
\hline
\end{tabular}

${ }^{a}(n / n)$ : sample size of Ever/Never.

${ }^{b} \mathrm{SD}$, standard deviations.

${ }^{c}$ creat., Creatinine.

${ }^{d}$ Significant difference.

buildings. Among studies, no single factor or group of factors has been regarded as the specific cause of SBS (Redlich et al., 1997). Burge (2004) has proposed a number of factors related to the increased prevalence of building symptoms; these factors included personal factors (female and working at lower hierarchy in building), individual factors (paper dust, cigarette smoke, office dust, and using computers), and building factors (high indoor temperature, low fresh air ventilation in office, poor control of temperature and lighting, air-conditioned building, poor building service maintenance, poor cleaning or cleanability, and water damage). Attention has been focused on the multiple exposures and sources of common contaminants in the indoor air (Redlich et al., 1997). The office air quality observation with self-reported symptoms by subjects in the present study may strengthen with the association between SBS and urinary 8-OHdG. Volatile organic compounds, environmental tobacco smoke, and carbon dioxide in the building may accumulate from insufficient ventilation rate. Low ventilation rate in room, environmental tobacco smoking (ETS), formaldehyde, carbon dioxide, and VOCs have been noticed in sick building syndrome (SBS) etiologic studies (Skov et al., 1989; Lyles et al., 1991; Norback \& Edling,
1991; Engvall et al., 2001; Kim et al., 2002; Bako-Biro et al., 2004; Pommer et al., 2004; Sari et al., 2004). Additionally, exposure to molds inside building has been associated with SBS (Straus et al., 2003; Burge, 2004; Ebbehoj et al., 2005; Laumbach \& Kipen, 2005). In this study, we failed to find such kind of association.

\section{TABLE 4}

Mean and standard deviation (SD) of urinary 8-hydroxydeoxyguanosine levels of study participants according to numbers of SBS symptoms

\begin{tabular}{lccc}
\hline $\begin{array}{l}\text { Number of } \\
\text { SBS symptoms }\end{array}$ & $n$ & $\begin{array}{c}\text { Mean (SD), } \\
\mu \mathrm{g} / \mathrm{g} \text { creat. }\end{array}$ & $p$ Value \\
\hline 0 & 184 & $5.45(3.10)$ & \\
1 & 90 & $5.11(3.02)$ & \\
2 & 48 & $5.79(3.44)$ & $<.001$ \\
$3-4$ & 45 & $7.36(4.38)$ & \\
$\geq 5$ & 22 & $8.81(4.52)$ & \\
\hline
\end{tabular}

Note. creat., Creatinine. 


\section{TABLE 5}

Crude and adjusted odds ratio of SBS symptoms associated with microgram per gram creatinine increase in urinary 8-hydroxydeoxyguanosine level

\begin{tabular}{llll}
\hline \multirow{2}{*}{ SBS $^{a}$} & \multicolumn{3}{c}{ Odds ratio $(95 \% \mathrm{CI})^{b}$} \\
\cline { 2 - 4 } symptom & Crude estimates & Adjusted estimates $^{c}$ \\
\hline Eye, any & $1.06(0.99-1.13)$ & $1.11^{d}(1.01-1.21)$ \\
$\quad$ eye dryness & $1.08^{d}(1.01-1.16)$ & $1.12^{d}(1.02-1.23)$ \\
eye irritation & $0.98^{d}(0.86-1.11)$ & 1.12 & $(0.93-1.36)$ \\
Upper respiratory, any & $1.24^{d}(1.15-1.34)$ & $1.17^{d}(1.05-1.30)$ \\
$\quad$ Nose itching & $1.18^{d}(1.03-1.36)$ & $1.25^{d}(1.02-1.53)$ \\
Runny nose & $1.16^{d}(1.01-1.34)$ & 1.22 & $(0.98-1.52)$ \\
Stuffy nose & $1.34^{d}(1.11-1.35)$ & 1.12 & $(0.97-1.29)$ \\
Sneezing & $1.22^{d}(1.06-1.40)$ & $1.51^{d}(1.21-1.87)$ \\
Dry throat & $1.22^{d}(1.11-1.34)$ & $1.21^{d}(1.06-1.38)$ \\
Lower respiratory, any & $1.00(0.89-1.11)$ & 0.97 & $(0.83-1.13)$ \\
$\quad$ Difficulty in & $1.00(0.89-1.11)$ & 0.97 & $(0.83-1.13)$ \\
$\quad$ breathing & & & \\
Skin, any & $1.34^{d}(1.12-1.60)$ & $1.31^{d}(1.04-1.65)$ \\
$\quad$ Dryness & $1.34^{d}(1.12-1.60)$ & $1.31^{d}(1.04-1.65)$ \\
Nonspecific, any & $1.13^{d}(1.06-1.20)$ & 1.05 & $(0.96-1.15)$ \\
Headache & $1.32^{d}(1.14-1.53)$ & 1.11 & $(0.77-1.60)$ \\
Tiredness & $1.17^{d}(1.09-1.25)$ & 1.03 & $(0.94-1.14)$ \\
Difficulty & $1.16^{d}(1.08-1.25)$ & 1.03 & $(0.93-1.15)$ \\
$\quad$ concentrating & & & \\
Angry easily & $1.16^{d}(1.08-1.25)$ & 0.99 & $(0.88-1.12)$ \\
Dizziness & $1.18^{d}(1.08-1.30)$ & $1.19^{d}(1.05-1.35)$ \\
\hline
\end{tabular}

${ }^{a}$ SBS, sick-building syndrome.

${ }^{b} 95 \%$ CI, $95 \%$ confidence interval.

${ }^{c}$ Adjusted for age, gender, presence of carpet in workspace, sensitivity to tobacco smoke and air pollutants, difference between indoor and outdoor carbon dioxide, and urinary cotinine concentrations.

${ }^{d}$ Significantly different.

Low ventilation rate in the room is thought to be the major cause of SBS symptoms (Bourbeau et al., 1997; Seppänen et al., 1999; Backman \& Haghighat, 1999; Apte et al., 2000). It has been found that the indoor volatile organic compounds exposure has a significant respiratory effect (Samet et al., 1987). And our further data analysis for nonsmokers did show that the urinary 8-OHdG levels of participants increased as the exposed TVOC and/or $\mathrm{CO}_{2}$ levels increased in the office (data not shown). We believe some of these common contaminants in offices are associated with oxidative stress leading to the generation of 8OHdG. Among previous SBS studies, no study has related SBS with increased level of urinary 8-OHdG.

In this study, the urinary 8-OHdG concentrations were significantly associated with volatile organic compounds and carbon dioxide levels measured in the offices. We also found that the 8 -OHdG concentration was higher in smokers, with an average of $10.9 \pm 4.0 \mu \mathrm{g} / \mathrm{g}$ creatinine, but it was somewhat lower than that observed for community smokers (Chuang et al., 2003). This study also showed that the concentrations of $\mathrm{CO}_{2}$ and volatile organic compounds at offices were higher than those in the air outside of the building.

Results of the current analyses suggest significant associations between urinary 8-OHdG levels and risks of certain SBS complaints among office workers, with ORs ranging between 1.11 and 1.51. Additionally, SBS complaints and 8-OHdG are both associated with indoor air pollutants such as carbon dioxide, volatile organic compounds, and tobacco smoke exposure. These findings were evident in adjusted MLR models through adjustment for potential confounders, such as gender, age, sensitivity to tobacco smoke and air pollutants, difference in carbon dioxide between indoor and outdoor, tobacco smoke exposure, the presence of carpet in workplace, and so on. The gradient relationship between number of symptoms and 8-OHdG concentrations in urine has strengthened our research hypothesis, that is, that $8-\mathrm{OHdG}$ can be a predictor for SBS. To our knowledge, this is the first observation of a positive association between SBS and the urinary 8-OHdG level. This study suggested that in urine $8-\mathrm{OHdG}$, a response to indoor oxidative chemicals, could be considered as a predictor to moderate the risks of certain SBS complaints including eye dryness, nose itching, sneezing, dry throat, dryness of skin and eye, dizziness, and upper respiratory syndromes in office employees. Because the etiology of SBS complaints has not been fully understood, the findings from this analysis cannot be dismissed and warrant further research.

\section{REFERENCES}

Anderson, R., Theron, A. J., Richards, G. A., Myer, M. S., and Van Rensburg, A. J. 1991. Passive smoking by human sensitizers circulating neutrophils. Am. Rev. Respir. 144:570-574.

Apte, M. G., Fisk, W. J., and Daisey, J. M. 2000. Associations between indoor $\mathrm{CO}_{2}$ concentrations and sick building syndromes in U.S. office buildings: An analysis of the 1994-1996 BASE study data. Indoor Air 10:246-247.

Backman, H., and Haghighat, F. 1999. Indoor-air quality and ocular discomfort. Am. Optom. Assoc. 70:309-316.

Bako-Biro, Z., Wargocki, P., Weschler, C. J., and Fanger, P. O. 2004. Effects of pollution from personal computers on perceived air quality, SBS symptoms and productivity in offices. Indoor Air 14:178-187.

Benowitz, N. L. 1996. Cotinine as a biomarker of environmental tobacco smoke exposure. Epidemiol. Rev. 18:188-203.

Bourbeau, J., Brisson, C., and Allaire, S. 1997. Prevalence of the sick building syndrome symptoms in office workers before and six months and three years after being exposed to a building with an improved ventilation system. Occup. Environ. Med. 54:49-53.

Burge, P. S. 2004. Sick building syndrome. Occup. Environ. Med. 61:185-190.

Calderon-Garciduenas, L., Wen-Wang, L., Zhang, Y. J., RodriguezAlcaraz, A., Osnaya, N., Villarreal-Calderon, A., and Santella, R. M. 1999. 8-Hydroxy-2'-deoxyguanosine, a major mutagenic oxidative DNA lesion, and DNA strand breaks in nasal respiratory epithelium of children exposed to urban pollution. Environ. Health Perspect. 107:469-474.

Carstensen, U., Hou, S. M., Alexandrie, A. K., Hogstedt, B., Tagesson, C., Warholm, M., Rannug, A., Lambert, B., Axmon, A., and Hagmar, 
L. 1999. Influence of genetic polymorphisms of biotransformation enzymes on gene mutations, strand breaks of deoxyribonucleic acid, and micronuclei in mononuclear blood cells and urinary 8hydroxydeoxyguanosine in potroom workers exposed to polyaromatic hydrocarbons. Scand. J. Work Environ. Health 25:351-360.

Chuang, C. Y., Lee, C. C., Chang, Y. K., and Sung, F. C. 2003. Oxidative DNA damage estimated by urinary 8-hydroxydeoxyguanosine: Influence of taxi driving, smoking and areca chewing. Chemosphere 52:1163-1171.

Ebbehoj, N. E., Meyer, H. W., Wurtz, H., Suadicani, P., Valbjorn, O., Sigsgaard, T., and Gyntelberg, F. 2005. Molds in floor dust, building-related symptoms, and lung function among male and female schoolteachers. Indoor Air 15:7-16.

Engvall, K., Norrby, C., and Norbäck, D. 2001. Sick building syndrome in relation to building dampness in multi-family residential buildings in Stockholm. Int. Arch. Occup. Environ. Health 74:270-278.

Floyd, R. A., West, M. S., Eneff, K. L., and Schneider, J. E. 1990. Mediation of 8-hydroxy-guanine formation in DNA by thiazin dyes plus light. Free Radical Biol. Med. 8:327-330.

Fraga, C. G., Shigenaga, M. K., Park, J. W., Degan, P., and Ames, B. N. 1990. Oxidative damage to DNA during aging: 8-hydroxy-2'deoxyguanosine in rat organ DNA and urine. Proc. Natl. Acad. Sci. USA 87:4533-4537.

Haufroid, V., and Lison, D. 1998. Urinary cotinine as a tobacco-smoke exposure index: A minireview. Int. Arch. Occup. Environ. Health 71:162-168.

Huang, M. F., Lin, W. L., and Ma, T. C. 2005. A study of reactive oxygen species in mainstream of cigarette. Indoor Air 15:135-140.

Kasai, H., Iwamoto-Tanaka, N., Miyamoto, T., Kawanami, K., Kawanami, S., Kido, R., and Ikeda, M. 2001. Life style and urinary 8-hydroxydeoxyguanosine, a marker of oxidative DNA damage: Effects of exercise, working conditions, meat intake, body mass index, and smoking. Jpn. J. Cancer Res. 92:9-15.

Kim, W. J., Terada, N., Nomura, T., Takahashi, R., Lee, S. D., Park, J. H., and Konno, A. 2002. Effect of formaldehyde on the expression of adhesion molecules in nasal microvascular endothelial cells: The role of formaldehyde in the pathogenesis of sick building syndrome. Clin. Exp. Allergy 32:287-295.

Kreiss, K. 1990. The sick building syndrome: Where is the epidemiologic base? Am. J. Public Health 80:1172-1173.

Laumbach, R. J., and Kipen, H. M. 2005. Bioaerosols and sick building syndrome: particles, inflammation, and allergy. Curr. Opin. Allergy Clin. Immunol. 5:135-139.

Levin, H. 1989. Building materials and indoor air quality. State of the art reviews. Occup. Med. 4:667-694.

Loft, S., Vistisen, K., Ewertz, M., Tjonneland, A., Overvad, K., and Poulsen, H. E. 1992. Oxidative DNA damage estimated by 8-hydroxydeoxyguanosine excretion in humans: Influence of smoking, gender and body mass index. Carcinogenesis. 13:2241-2247.

Lyles, W. B., Greve, K. W., Bauer, R. M., Ware, M. R., Schramke, C. J., Crouch, J., and Hicks, A. 1991. Sick building syndrome. South Med. J. 84:65-71.

Mahmoudi, M., and Gershwin, M. E. 2000. Sick building syndrome. III. Stachybotrys chartarum. J. Asthma. 37:191-198.

Menzies, D., Pasztor, J., Nunes, F., Leduc, J., and Chan, C. H. 1997. Effect of a new ventilation system on health and well-being of office workers. Arch. Environ. Health 52:360-367.

Niven, R. M., Fletcher, A. M., Pickering, C. A. C., Faragher, E. B., Potter, I. N., Booth, W. B., Jones, T. J., and Potter, P. D. R. 2000.
Building sickness syndrome in healthy and unhealthy buildings: an epidemiological and environmental assessment with cluster analysis. Occup. Environ. Med. 57:627-634.

Nerurkar, M. K., and Sahasrabudhe, M. B. 1960. Synthesis of creatine in X-irradiated rats. Int. J. Radiat. Biol. 2:237-246.

Norback, D., and Edling, C. 1991. Environmental, occupational, and personal factors related to the prevalence of sick building syndrome in the general population. Br. J. Ind. Med. 48:451-462.

Pommer, L., Fick, J., Andersson, B., Sundell, J., Nilsson, C., Sjöström, M., and Stenberg, B. 2004. Class separation of buildings with high and low prevalence of SBS by principal component analysis. Indoor Air 14:16-23.

Redlich, C. A., Sparer, J., and Cellen, M. R. 1997. Sick-building syndrome. Occup. Med. 349:1013-1016.

Samet, J. M., Marbury, M. C., and Spingler, J. D. 1987. Respiratory effect of indoor air pollution. J. Allergy Clin. Jmmunol. 79:685-700.

Sari, D. K., Kuwahara, S., Tsukamoto, Y., Hori, H., Kunugita, N., Arashidani, K., Fujimaki, H., and Sasaki, F. 2004. Effect of prolonged exposure to low concentrations of formaldehyde on the corticotropin releasing hormone neurons in the hypothalamus and adrenocorticotropic hormone cells in the pituitary gland in female mice. Brain Res. 1013:107-116.

Seidner, A. 1999. Sick building syndrome. Hosp. Pract. 15:127-129.

Seppänen, O. A., Fisk, W. J., and Merdell, M. J. 1999. Association of ventilation rates and $\mathrm{CO}_{2}$ concentrations with health and other responses in commercial and institutional buildings. Indoor Air 9:226252.

Shigenaga, M. K., Gimeno, C. J., and Ames, B. N. 1989. Urinary 8-hydroxy-2'-deoxyguanosine as a biological marker of in vivo oxidative DNA damage. Proc. Natl. Acad. Sci. USA 86:9697-9701.

Skov, P., Valbjørn, O., and Pedersen, B. V. 1989. Influence of personal characteristics, job-related factors and psychosocial factors on the sick buildibg syndrome. Scand. J. Work Environ. Health 15:286295.

Straus, D. C., Cooley, J. D., Wong, W. C., and Jumper, C. A. 2003. Studies on the role of fungi in sick building syndrome. Arch. Environ. Health 58:475-478.

Tagesson, C., Kallberg, M., Klintenberg, C., and Starkhammar, H. 1995. Determination of urinary 8-hydroxydeoxyguanosine by automated coupled-column high performance liquid chromatography: A powerful technique for assaying in vivo oxidative DNA damage in cancer patients. Eur. J. Cancer 31A:934-940.

Tagesson, C., Kallberg, M., and Wingren, G. 1996. Urinary malodialdehyde and 8-hydroxydeoxyguanosine as potential markers of oxidative stress in industrial art glass workers. Int. Arch. Occup. Environ. Health 69:5-13.

Tearle, P. 1999. The sick building syndrome. Commun. Dis. Public Health 2:303-304.

Teculescu, D. B., Sauleau, E. A., Massin, N., Bohadana, A. B., Buhler, O., Benamghar, L., and Mur, J. M. 1998. Sick-building symptoms in office workers in northeastern France: A pilot study. Int. Arch. Occup. Environ. Health 71:353-635.

van Klaveren, R. J., and Nemery, B. 1999. Role of reactive oxygen species in occupational and environmental obstructive pulmonary diseases. Curr. Opin. Pulm. Med. 5:118-128.

van Zeeland, A. A., de Groot, A. J., Hall, J., and Donato, F. 1999. 8-Hydroxydeoxyguanosine in DNA from leukocytes of healthy adults: Relationship with cigarette smoking, environmental tobacco smoke, alcohol and coffee consumption. Mutat. Res. 439:249-257. 
Willers, A., Hein, H. O., and Jansson, L. 2004. Assessment of environmental tobacco smoke exposure: Urinary cotinine concentrations in children are strongly associated with the house dust concentrations of nicotine at home. Indoor Air 14:83-86.

Wilson, V. L., Taffe, B. G., Shields, P. G., Povey, A. C., and Harris, C. C. 1993. Detection and quantification of 8-hydroxydeoxyguanosine adducts in peripheral blood of people exposed to ionizing radiation. Environ. Health Perspect. 99:261-263.

Witherell, H. L., Hiatt, R. A., Replogle, M., and Parsonnet, J. 1998. Helicobacter pylori infection and urinary excretion of 8-hydroxy2-deoxyguanosine, an oxidative DNA adduct. Cancer Epidemiol. Biomarkers Prev. 7:91-96.
World Health Organization. 1986. Indoor Air Quality Research, EURO reports and studies, p. 103. Copenhagen, Denmark: WHO Regional Office for Europe.

Wu, L. L., Chiou, C. C., Chang, P. Y., and Wu, J. T. 2004. Urinary 8-OHdG: A marker of oxidative stress to DNA and a risk factor for cancer, atherosclerosis and diabetics. Clin. Chim. Acta 339:1-9.

Yassi, A., Kjellström, T., de Kok, T., and Guidotti, T. L. 2001. Basic environmental health, pp. 291-292. London: Oxford University Press.

Yin, B., Whyatt, R. M., Perera, F. P., Randall, M. C., Cooper, T. B., and Santella, R. M. 1995. Determination of 8-hydroxydeoxyguanosine by an immunoaffinity chromatography-monoclonal antibody-based ELISA. Free Radical Biol. Med. 18:1023-1032. 
Copyright of Inhalation Toxicology is the property of Taylor \& Francis Ltd and its content may not be copied or emailed to multiple sites or posted to a listserv without the copyright holder's express written permission. However, users may print, download, or email articles for individual use. 